\title{
A NOTE ON "MORE FOR LESS" PARADOX IN RELATION TO ECONOMIC PROBLEMS
}

The More for Less Paradox is not only an interesting theoretic construction. An optimization problem, which has this interesting property, can also be found in the real economic world. This contribution was stimulated by the paper [4], which results from the contribution [1] and [2] discussing one interesting property of the linear programming models behaviour, and comments on it and discusses it further. In the paper we attempt to show on a concrete case of a real practical problem [5] that similar property does not need to be a purely theoretical plaything, and it can also be spotted when analysing different variants of a real problem solution.

\section{Introduction}

The contribution discusses one interesting property of some linear programming problems known in literature as "More for Less Paradox". In the opening chapters the substance of this paradox and some further connection related to this phenomenon are described briefly. The following parts of the contribution demonstrate that it is also possible to find some characteristics analogous to "More for Less" paradox in individual practical problems. The purpose is to point out that even rather extensive practical problems can show an analogue with simple theoretical model properties.

\section{Substance of the "More for Less Paradox"}

Suppose the firm uses $n$ different manufacturing processes $T_{1}$, $T_{2}, \ldots T_{n}$ (it is technologies, production programs, cutting schedules, etc.) to produce the required amounts of $m$ different products. Each manufacturing process $j$ is described by the output coefficient $a_{i j}$, indicating the amount of product $i$ by using just one unit of the manufacturing process $T_{j}$. Further the required output numbers $b_{i}$ of product $i$, and $\operatorname{costs} c_{j}$ per unit of the manufacturing process $T_{j}$ are known. The decision-making problem for a firm is, what manufacturing processes to apply and in what frequency in order to produce the required amount of products at minimal costs.

This decision-making problem can be formulated as following linear model, where $x_{j}$ means the number of units of the manufacturing process $T_{j}$ used:

$$
\begin{array}{ll}
\operatorname{minimize} & z(\boldsymbol{x})=\sum_{j=1}^{n} c_{j} x_{j} \\
\text { subject to } & \sum_{j=1}^{n} a_{i j} x_{j}=b_{i}, \quad i=1,2, \ldots m \\
& x_{j} \geq 0, \quad j=1,2, \ldots n
\end{array}
$$

The above paradox consists in the fact that for a number of the concrete queries for the some values of the matrix $\boldsymbol{A}=\left\{a_{i j}\right]$ and the cost vector $c=\left\{c_{j}\right]$ is possible to find (depending on the values of the two different required output vectors $\boldsymbol{b}^{1}=\left\{b_{i}^{1}\right\}$ and $\left.\boldsymbol{b}^{2}=\left\{b_{i}^{2}\right\}\right)$ such two optimal solutions $\boldsymbol{x}_{\text {opt }}^{1}$ and $\boldsymbol{x}_{\text {opt }}^{2}$ of the problem (1) - (3), and so the following applies:

$$
b_{i}^{1} \geq b_{i}^{2} \quad \text { for all } \quad i=1,2, \ldots m,
$$

and simultaneously

$$
z\left(x_{o p t}^{1}\right)<z\left(x_{o p t}^{2}\right) .
$$

In other words, it is possible to achieve higher (it is "MORE") or even level of production for all products at lower total cost ("FOR LESS").

We can outline the above-mentioned situation using the specific example presented in [4]:

Suppose model (1) - (3) with $m=2$ and $n=6$, where the output coefficient matrix $\boldsymbol{A}$ is given:

$$
A=\left(\begin{array}{lllll}
3 & 2 & 1 & 2 & 4 \\
1 & 1 & 2 & 2 & 5
\end{array}\right)
$$

The required output numbers of the products are given by the vector $\boldsymbol{b}^{1}=(15,5)$, and the expenses per unit of the manufacturing process $T_{j}$ are given by the vector $c=(5,3,3,4,6)$. Then the optimal solution of the problem (1) - (3) leads to $\boldsymbol{x}_{\text {opt }}^{\mathbf{1}}=(5,0,0$, $0,0)$ with the objective function value $z\left(x_{o p t}^{1}\right)=25$. However if the required output numbers of the products increase from $\boldsymbol{b}^{1}=(15$, 5 ) to the values $\boldsymbol{b}^{2}=(16,20)$, the optimal production programme of the firm will be the application of the visibly most expensive manufacturing process $T_{6}$ at solution $x_{o p t}^{2}=(0,0,0,0,4)$ whereas total cost value decreases form 25 to the value $z\left(x_{\text {opt }}^{2}\right)=24$. This means that with the production increase of both the first product by $6,7 \%$ and the second product by $300 \%$, the total cost will decrease by $4 \%$.

\footnotetext{
* Miroslav Plevný

Department of Statistics and Operations Research, Faculty of Economics, University of West Bohemia in Pilsen, Hradební 22, 35011 Cheb,

Czech Republic; E-mail: miroslav.plevny@fek.zcu.cz
} 


\section{Some further comments to the solution showing the above paradox}

The explanation of the paradox occurrence described in the previous chapter is trivial. The principal point is that we have to choose the expensive manufacturing processes at the expense of keeping the required combination of output products number. Such combinations of the output product number may exist that seen from the production cost point of view they are cheaper even with a higher number of manufactured products (compare required outputs $\boldsymbol{b}^{1}$ and $\boldsymbol{b}^{2}$ with the characteristics of the particular manufacturing processes $T_{1}, T_{2}, \ldots T_{6}$ ).

Further on it is possible to state that it is possible to prevent an occurrence of the presented paradox in the model (1) - (3) simply if we substitute the constraints (2) by the constraints:

$$
\sum_{j=1}^{n} a_{i j} x_{j} \geq b_{i}, \quad i=1,2, \ldots m .
$$

The model:

$$
\begin{aligned}
& \text { minimize } \\
& \text { subject to }
\end{aligned}
$$

allows all the combinations of the output product numbers with an even or higher production level than the limit numerical values $b_{i}$ for all products $i=1,2, \ldots m$. So the found optimal solution shows from the point of the objective function value the features of the global minimum for all these combinations of the output product numbers, and thus the occurrence of the mentioned paradox is not possible.

\section{Connection with shadow prices}

The fact that the problem (1) - (3) shows the "more for less" property is possible to identify simply by means of the shadow prices of this problem. It is obvious that if the given problem solution has to show the characteristics of the above paradox, the increase of at least one right-hand-side value $b_{k}$ of the constraints
(2) has to be possible with simultaneous non-decreasing of other values $b_{i},(i=1,2, \ldots m ; i \neq k)$ so that the objective function value (1) decreases at the same time.

From the point of view of the definition of the shadow price value (see e.g. [3, pgs. 74-77]) for the above $k^{\text {th }}$ constraint of the model (1) - (3) it means that this shadow price is negative.

It is obvious at the same time that in case of the model (1), (4), (3) such an instance cannot arise. This statement results from the feature of this model (the minimization problem, all constraints are of the type „, $\geq$ ", and all variables are non-negative), for which all the optimal solution variable values of the corresponding dual problem - it is shadow prices for primary problem - necessarily have to be non-negative (if there is any optimal solution at all).

\section{Characteristics of the analyzed concrete example}

The property of the optimization problem solution presented in the previous chapters need not be a purely theoretical plaything. Analysing the different solution variations of the chosen concrete practical problems, we can notice some analogical features in the interrelationship of some solutions of the given problem.

We will try to demonstrate it on a concrete problem, which we recently solved by means of linear programming [5]. It was a case of a wood-processing company consisting of two main workplaces: a sawmill and a shop. Besides the finished lumber for direct sale the sawmill supplies wooden lamellae to be processed in the shop. It is possible to buy further lamellae from other subjects if necessary for the manufacturing in the shop. In principle, both workplaces can operate independently from each other in the form of one to three-shift modes. The objective of the study was to pass a judgment on the company production schedule in terms of general efficiency at different alternatives of shift working.

The constructed linear model is described in [5] in detail. Here we present just the resulting objective function values ( $=$ the total profit) for the optimal solution of the constructed model, which were gained based on the concrete shift-working mode (see Table

Optimal solution of given problem depending on shift working

Table 1

\begin{tabular}{|c|c|c|c|c|c|c|c|}
\hline \multirow{2}{*}{ Combina-tion No. } & \multicolumn{2}{|c|}{ Number shift } & \multirow{2}{*}{$\begin{array}{c}\text { Profit } \\
{[\text { SZK] }}\end{array}$} & Combina-tion No. & \multicolumn{2}{|c|}{ Number of shift } & Profit \\
\cline { 2 - 7 } & Saw-mill & Shop & & Saw-mill & & Saw-mill \\
\hline 1 & 0 & 0 & $-200000,-$ & 9 & 1 & 2 & $+916521,-$ \\
\hline 2 & 1 & 0 & $-311320,-$ & 10 & 1 & 3 & $+954921,-$ \\
\hline 3 & 2 & 0 & $-333433,-$ & 11 & 2 & 1 & $+1217559,-$ \\
\hline 4 & 3 & 0 & $-467745,-$ & 12 & 2 & 2 & $+1380085,-$ \\
\hline 5 & 0 & 1 & $-241000,-$ & 13 & 2 & 3 & $+1421085,-$ \\
\hline 6 & 0 & 2 & $-99600,-$ & 14 & 3 & 1 & $+1461027,-$ \\
\hline 7 & 0 & 3 & $-269700,-$ & 15 & 3 & 2 & $+1645169,-$ \\
\hline 8 & 1 & 1 & $+765521,-$ & 16 & 3 & 3 & $+1686169,-$ \\
\hline
\end{tabular}




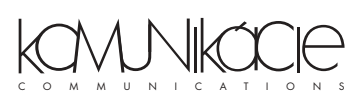

1 - the results for in total 16 variations of shift-working in both workplaces taken into account).

\section{Economic analysis of the resulting solution and connection with the above paradox}

As the introduced concrete solved problem is a maximization model, we can by means of analogy to the presented model (1) (3) consider the paradox occurrence, if higher aggregate gains are achieved at lower shift number. It is evident in the Table 1 that this situation occurs for all cases of the isolated saw-mill operation, when with the shift number increasing the gain goes down, i.e. the loss increases (see combination Nos. 2 - 4). Similar effect can be seen for the isolated hall operation (except the two-shift operation - combination No. 6) when the three-shift operation gain is worse than the gain from the one- or two-shift operation (see combination Nos. 5 - 7).

According to the obtained solution it is possible to achieve the highest total profit at $16^{\text {th }}$ shift working combination, i.e. at threeshift operation in both workplaces.

It could be misleading and even shortsighted to close the solution of the above problem by this rigorous statement of facts. It is well known that the application of the three-shift operation in companies, which cannot afford to have a reserve production facility, and usually do not operate in parallel running production lines, can be highly hazardous. It is impossible to compensate for an accidental production line breakdown, which can threaten the whole production process including holdbacks of other connected production lines. Using the three-shift operation we usually have a limited time left for prevention and diagnostics, whereby the breakdown risk increases. A possible operation failure cannot be caught up with a short-term productions increase by using additional shift. This is the case of the shop operation for the analyzed company in this study, where the high cost equipment is meant to glue the prisms.

Just in the case of the three-shift operation a realistic estimation of the anticipated profit for the company is necessary as well as considering a number of the above-mentioned hard to quantifiable limitations also, which wasn't included in the solved mathematical model.

Comparing the combination No. 13 and 14 it becomes evident that the use of one additional sawmill shift compensates for the two-shift decrease in the shop (see combination No. 10 and 11). This fact is very important in the context of the above-discussed problem of the three-shift shop operation, which is highly hazardous in case of any production disturbances. In case of disturbances and subsequent shop shutdown we come instantly to loss-making production schedules No. 1 - 4 .

On the basis of the previous point it is possible to state that despite the found optimal solution for combination No. 16, the appropriate recommendation for the company operation can be the shift combination No. 15 (it is sawmill - 3 shift, shop - 2 shift). The total production profit calculated by the mathematical model can be lower only by $2.5 \%$.

If it is necessary to reduce production (distribution difficulties, lack of input etc.) the shift combination No. 14 seems relatively profitable, where the profit is lower of about less than $13.5 \%$ at production volume decrease (in $\mathrm{m}^{3}$ ) of $25.5 \%$.

These findings did not directly reflect the "more for less paradox" properties discussed in this paper already, nevertheless some analogies can certainly be found here. We tried to point out a possible connection between the solution of rather extensive existing problems in economic reality, and some properties of the simple theoretical models, which seem to be artificial and impractical at the first glance.

\section{References}

[1] CHARNES, A., DUFFUAA, S. and RYAN, M.: The more for less paradox in linear programming. European Journal of Operational Research 31 (1987), pp. 194-197. ISSN 0377-2217.

[2] CHOBOT, M., TURNOVEC, F.: One economic paradox in linear programming models. Ekonomicko-matematický obzor 4, 1974, pp. 374-386. ISSN 0013-3027 (in Slovak language).

[3] JABLONSKÝ, J.: Operations Research - Quantitative Models for Economics Decision Making (Operační výzkum - Kvantitativní modely pro ekonomické rozhodování). Praha: Professional Publishing, 2002, p. 323. ISBN 80-86419-23-1 (in Czech language).

[4] LUPTACIK, M.: A Note on the "More-for-Less" Paradox. In: KISCHKA, P. ... (ed.) Models, Methods and Decision Support for Management. Heidelberg, New York: Physica-Verlag, 2001, pp. 103-109. ISBN 3-7908-1373-7.

[5] PLEVNÝ, M.: Small Decision Problems in Logistics-Management and their Effective Solution. In: Mathematical Methods in Economics 2002 - Proceedings of the $20^{\text {th }}$ International Conference, Sept. 3-5, 2002, Ostrava, pp. 215-222. ISBN 80-248-0153-1. 